ARTIFICIAL SATELLITES, Vol. 43, No. 4 - 2008

DOI: 10.2478/v10018-009-0014-7

\title{
ACCURACY ASSESSMENT OF DIGITAL ELEVATION MODELS USING GPS
}

\author{
Ashraf Farah \\ Assistant Professor, Aswan-Faculty of Engineering, South Valley University, Egypt \\ ashraf_farah@yahoo.com \\ Ashraf Talaat \\ Demonstrator, Aswan-Faculty of Engineering, South Valley University, Egypt \\ ash230eg@yahoo.com \\ Farrag A. Farrag \\ Professor, Faculty of Engineering, Assiut University, Egypt
}

\begin{abstract}
A Digital Elevation Model (DEM) is a digital representation of ground surface topography or terrain with different accuracies for different application fields. DEM have been applied to a wide range of civil engineering and military planning tasks. DEM is obtained using a number of techniques such as photogrammetry, digitizing, laser scanning, radar interferometry, classical survey and GPS techniques. This paper presents an assessment study of DEM using GPS (Stop\&Go) and kinematic techniques comparing with classical survey. The results show that a DEM generated from (Stop\&Go) GPS technique has the highest accuracy with a RMS error of $9.70 \mathrm{~cm}$. The RMS error of DEM derived by kinematic GPS is $12.00 \mathrm{~cm}$.
\end{abstract}

\section{Keywords: 1 . DEM $\quad$ 2. Stop \& Go $\quad$ 3. Kinematic $\quad$ 4.GPS}

\section{INTRODUCTION}

The term "digital elevation model" (DEM) is used to mean the digital cartographic representation of the elevation of the earth surface in any form. It is sometimes also referred as a "digital terrain model" (DTM). The (horizontal) spacing is specified in arc-seconds, with a smaller horizontal spacing usually implying a better resolution in height - though the height accuracy is actually a function of the production methods (Greve and American Society for Photogrammetry \& Remote Sensing., 1996; Mikhail et al., 2001).

DEM has been applied to a wide range of civil engineering and military planning tasks. DTM has also been used in many areas such as industry, medicine, architecture, mining, agriculture, mapping (Habib, 2005). These fields include (Y1lmaz et al., 2006)

- Planning of transportation and optimization of transportation

- Planning of irrigation and drainage work

- Analyze of communication network

- Planning of dam area

- Planning of measurement network 
- Land information system

- Navigation and direction

- City and region planning

- Disaster emergence planning

- Erosion control

- Evaluation of mining reserves

- Planning of use of weapon system

- Determination of radar cover area

- Three-dimensional city modelling

- Digital orthophoto map production

Many techniques are used for generation of DEM's with varying accuracies such as photogrammetry, digitizing, laser scanning, radar interferometry and classical field survey (Blomgren, 1999; Sugumaran et al., 2000). Currently the majority of DEMs are generated by photogrammetric methods. Besides the conventional photogrammetric and field surveying techniques, the new technologies of radar interferometry, or so-called interferometric synthetic aperture radar (InSAR), and airborne laser scanning (ALS) can also be used to generate high quality DEMs however the high cost for such techniques limits its use.

Classical survey methods such as total stations are used historically for producing DEM's with high accuracy for civil engineering applications however they are time and cost consuming. GPS technology is offering an efficient tool for producing DEM's especially for developing countries due to its accuracy and cost-effectivness comparing with other modern techniques which require higher cost and special experience. GPS could be used with both techniques (stop\&go) and kinematic for producing DEM's. Real time kinematic GPS systems can deliver almost instantaneous point coordinates with centimetre-level accuracy (Riley et al., 2000). RTK positioning uses a static GPS receiver as a reference station located at a known point. Another receiver is used as the rover which can move and survey any points of interest. Both receivers make observations of the GPS signals at the same time and a radio data link between the two receivers permits data to be sent from reference to rover, where the calculation of coordinates is carried out. For the desire of cost saving, when there is no need for instantaneous point coordinates, post processed kinematic GPS systems could be used as well. In this case there is no need for transmitting data between two receivers, instead the two data files from reference station and the rover are processed later on.

This paper presents accuracy assessment study for using post processed-GPS technology with its two techniques (stop\&go) and kinematic for producing DEM for an area of $100 \mathrm{~m}$ by $100 \mathrm{~m}$ at new Aswan city, Egypt which is a rural proposed site for attracting population from the old town of Aswan. The system used during GPS process of collecting observations was ProMark3 GPS system. ProMark3 system is L1 C/A code and carrier with Kinematic Survey Performance. The Reference station was set up on one corner of the study area. The used processing software is the GNSS Solutions version 2.00.03.

\section{GPS TECHNIQUES FOR DEM GENERATION}

GPS technology uses two main techniques for collecting observations which are static and kinematic techniques. The GPS kinematic technique of collecting observations is the one which is effective in the process of DEM generation. The kinematic data collection process requires at 
least two receivers collecting data simultaneously. One receiver is called the base and must remain stationary throughout the data collection. Typically, the base receiver will occupy a survey point for which the precise position is already known. Once operational, the base system simply collects and stores raw data from all satellites with line of sight to the GPS antenna. The kinematic base is essentially the same as a static occupation except that the recording interval should be set to match that of the kinematic rover. The other simultaneously operating GPS receiver(s) during a kinematic survey is (are) designated as the rover(s). The rover unit(s) can move during the survey and are used to position new points relative to the base. There are two types of kinematic survey supported by most receiver's types:

- Stop \& Go (sometimes it refers to rapid static as well)

- Continuous kinematic (simply kinematic)

Stop-and-go surveying is best suited for collection of points. During Stop-and-go, the system is centered over a point and collects data for a period of time. The occupation time for stop-andgo will typically range from 15-60 seconds.

Continuous kinematic data collection is suited for collecting bulk points with minimal attributing (terrain modelling) or linear features such as a road centerline. During continuous kinematic data collection the user never has to stop moving. A point is collected every time the receiver records a data record. The recording interval for this application would typically be 1-5 seconds, and the accuracy is typically 0.03 to 0.05 meters. The rover system is designed to be carried easily and is mounted entirely to a range pole. The system software interface is provided by the on-board data collector of the receiver unit. Essential system functionality such as data recording and data attributing are operated with the control buttons. Kinematic data collection has the advantage of high productivity.

\section{STUDY AREA AND MEASURMENTS}

The studied area is a rural area sited in new Aswan city, Egypt with an area of $100 \mathrm{~m}$ by $100 \mathrm{~m}$. The area was divided into 11 points (east-west) and (north-south) directions with a distance of 10 $\mathrm{m}$ between every two consecutive points. The total number of points was 122 points. The elevation of those 122 points was computed using three techniques;

- TOPCON GTS-712 total station.

- $\quad$ GPS (Stop\& Go) technique

- $\quad$ GPS kinematic technique

The system used during GPS process of collecting observations were ProMark3 GPS system ProMark3 system is L1 C/A code and carrier with Kinematic Survey Performance. Its typical accuracy is following:

- Horizontal: $0.012 \mathrm{~m}+2.5 \mathrm{ppm}(0.039 \mathrm{ft}+2.5 \mathrm{ppm})$

- Vertical: $0.015 \mathrm{~m}+2.5 \mathrm{ppm}(0.049 \mathrm{ft}+2.5 \mathrm{ppm})$

\section{1 (STOP\&GO) TECHNIQUE FIELD PCOCEDURE}

During collecting observations process using stop\&go technique the reference receiver was sited on point 1 (north-west corner). An initialization process was executed by bar for 5 minutes, this initialization time is an important to ensure centimeter-level accuracy (Promark 3.0 manual, 2005). The time occupied by the observer at single point was 15 seconds with 1 second recording 
interval in the base receiver and the rover receiver. Number of satellites was between $8-10$ and PDOP value was between $2-3.50$.

\subsection{KINEMATIC TECHNIQUE FIELD PCOCEDURE}

During collecting observations process using kinematic technique the reference receiver was sited on point 1 (north-west corner). An initialization process was exceeded by bar for 5 minutes. The recording interval was 5 seconds in the base receiver and the rover receiver. Number of satellites was between $11-12$ and PDOP value was between 1.6 - 1.7.

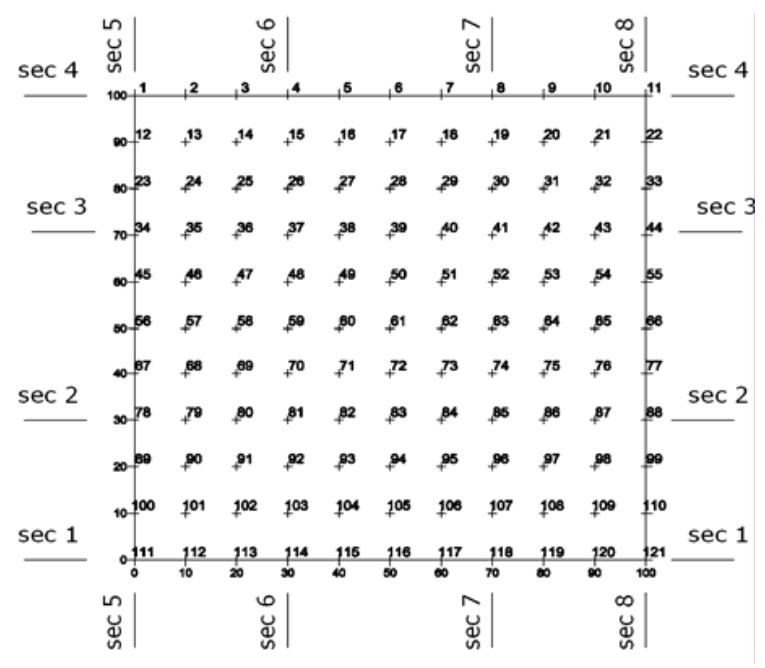

Fig. 1. Study Area with chosen cross sections in both directions.

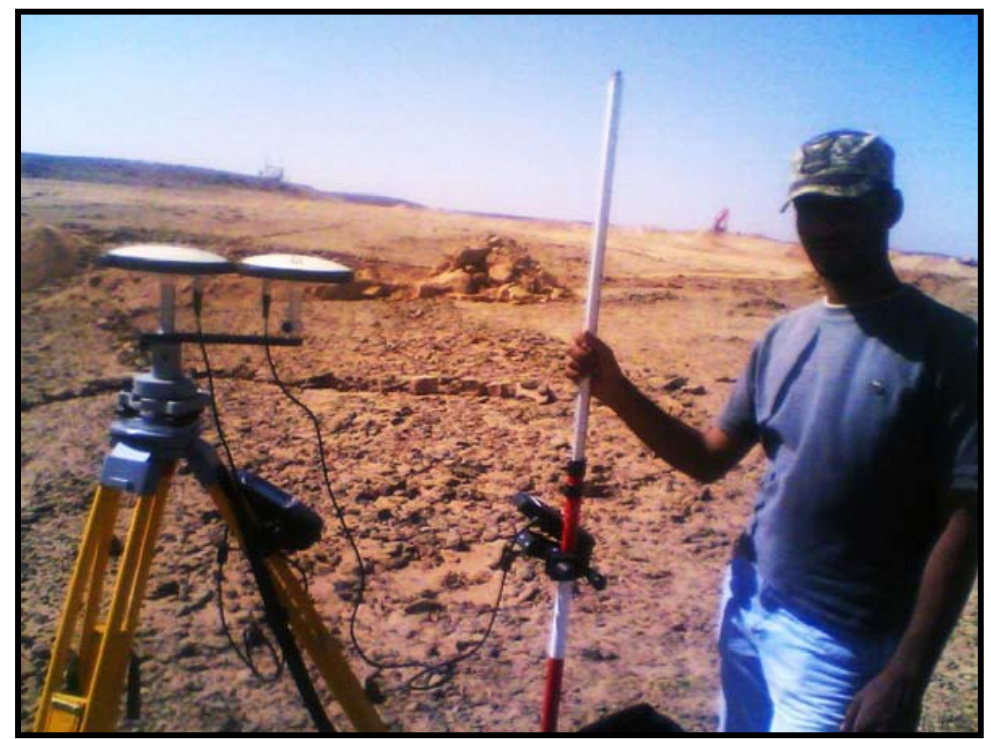

Fig. 2. Initialization by bar setup at Reference point 


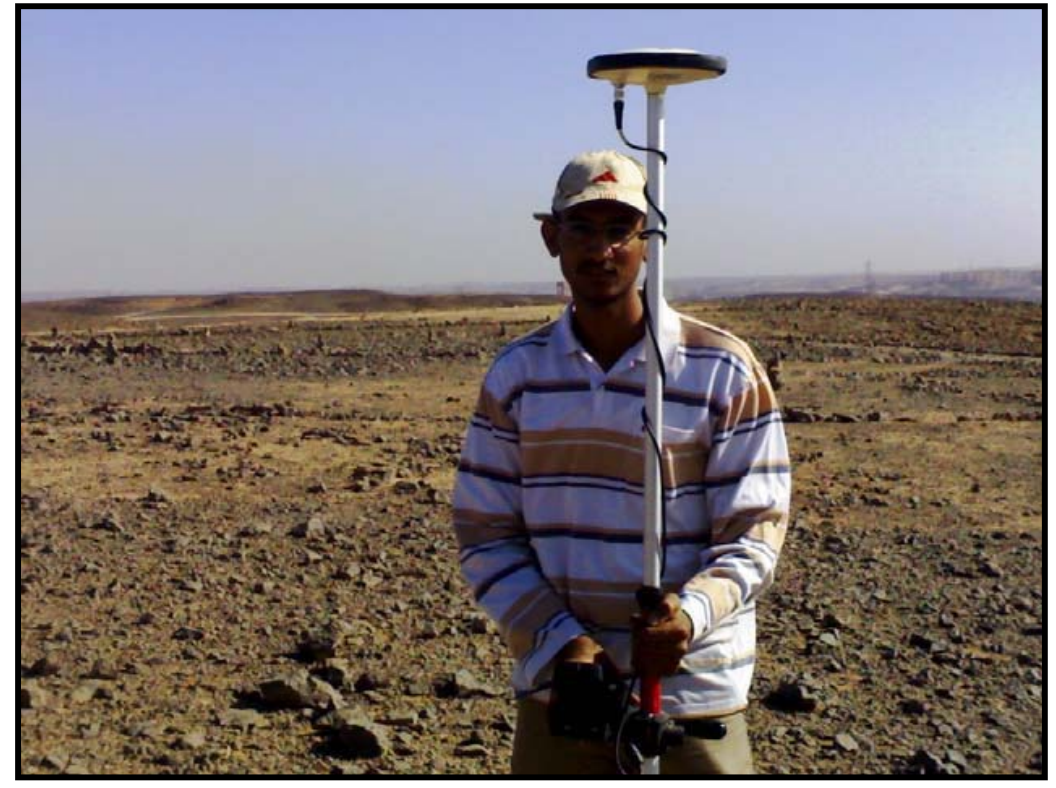

Fig. 3. Rover setup during (stop\&go) and kinematic survey

\section{STUDY OUTPUTS}

DEM of study area with Kriging interpolation technique was obtained via classical measurements, (Stop\&Go) GPS and kinematic GPS method (Figure 4). Visualisation of study area with contour lines by classical measurements and coordinates obtained from (Stop\&Go) GPS and kinematic GPS methods are given in Figure 5.

Four Cross sections passing in West-East and South-North directions were created and points were determined in $10 \mathrm{~m}$ intervals. Heights of these points determined according to contour lines with its differences are shown in Figures 6 to 13. The maximum, minimum, standard deviation and root mean square values for height difference from all observed points for both GPS techniques (classical measurements taken as reference) are shown in Table 1. Table 2 shows the same statistical analysis for the selective sections. 

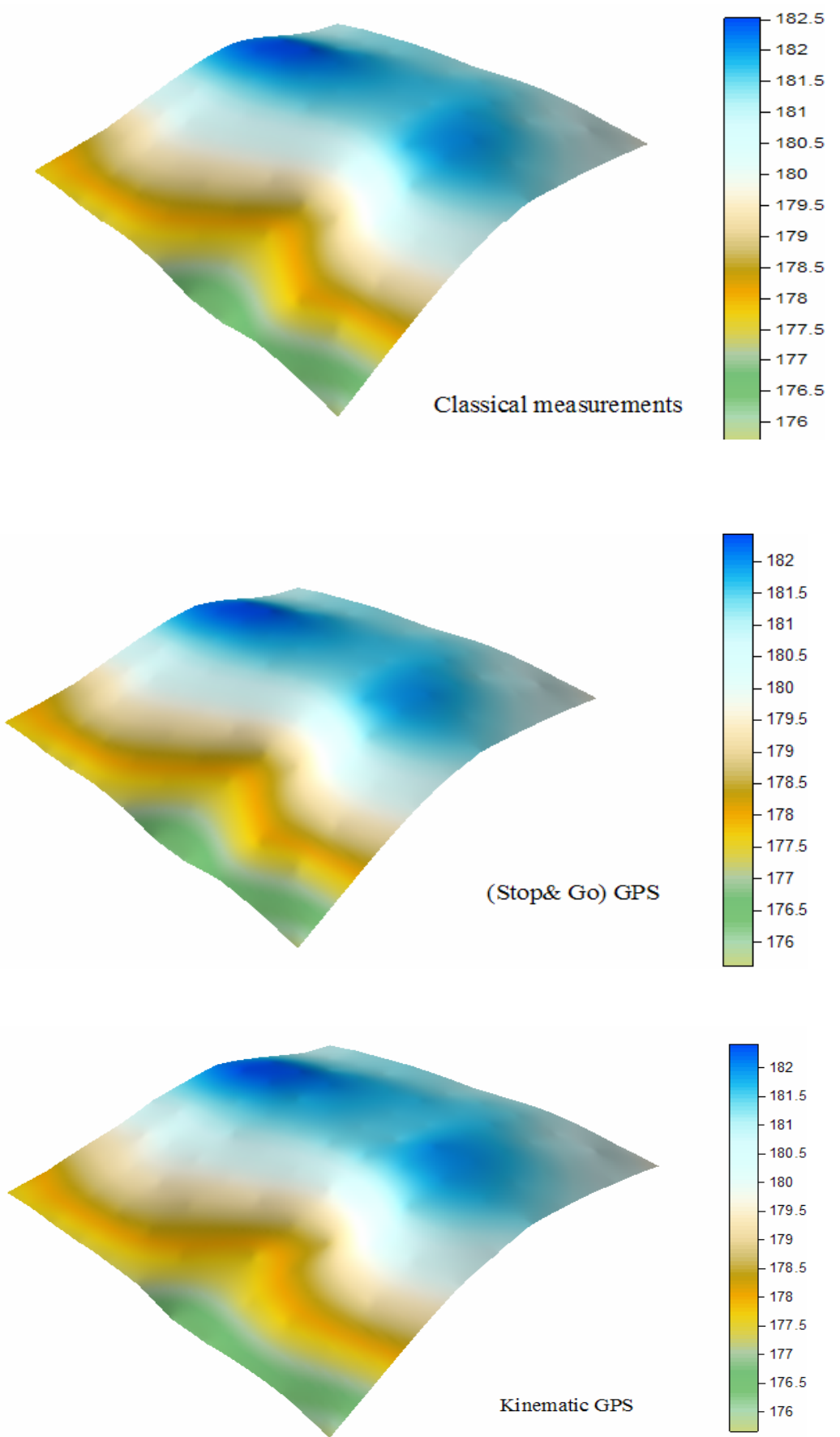

Fig. 4. DTM obtained from classical measurements, (Stop\&Go) GPS and Kinematic GPS 


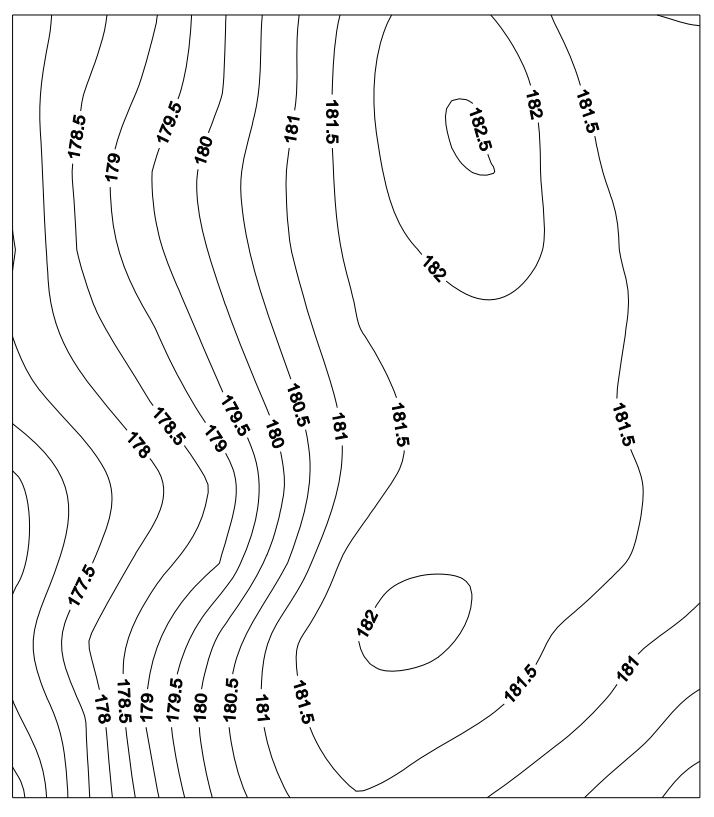

Classical measurements

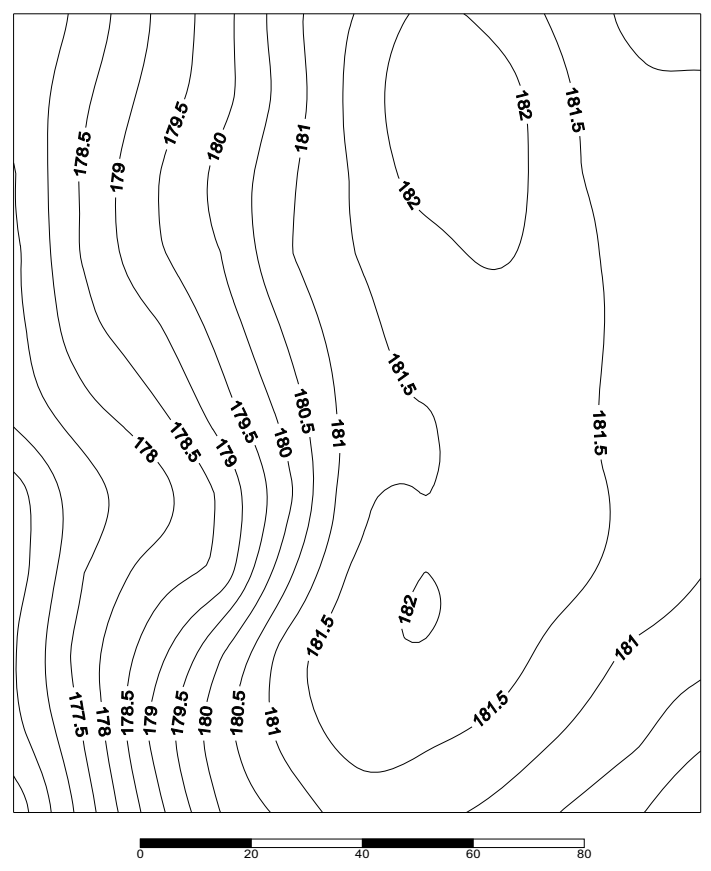

Kinematic GPS
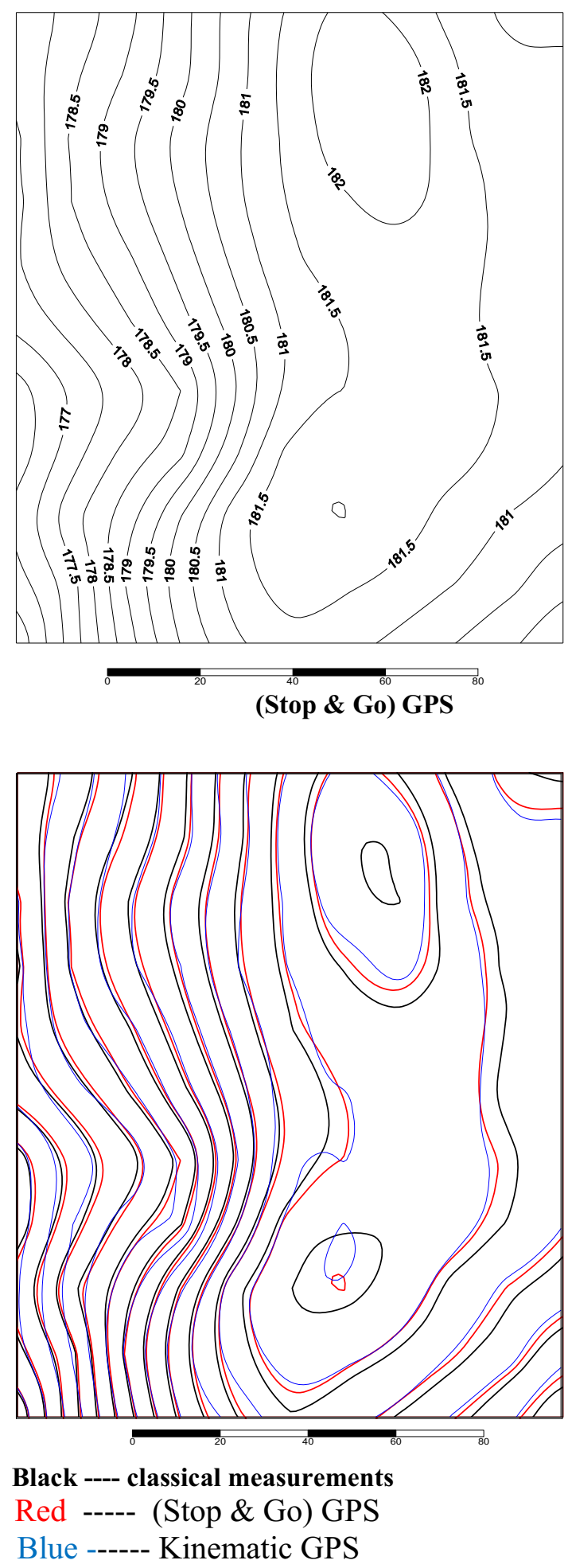

Black ---- classical measurements

Blue ------ Kinematic GPS

Fig. 5. Contour lines obtained from classical measurements, (Stop\&Go) GPS and Kinematic GPS 

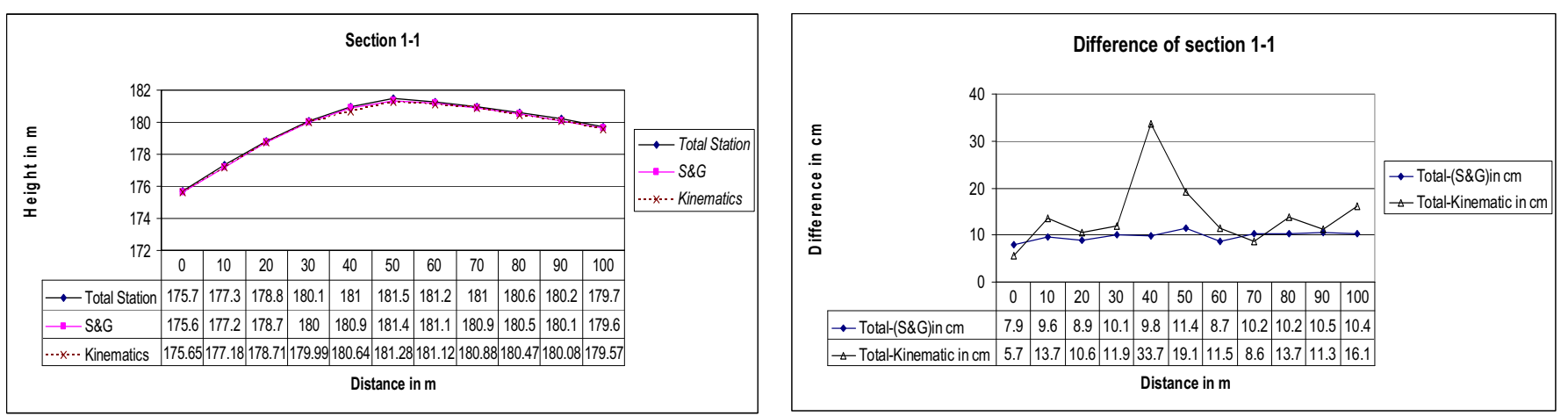

Fig. 6. Section (1-1) heights and height-difference from classical meas., (Stop\&Go) and Kin. GPS
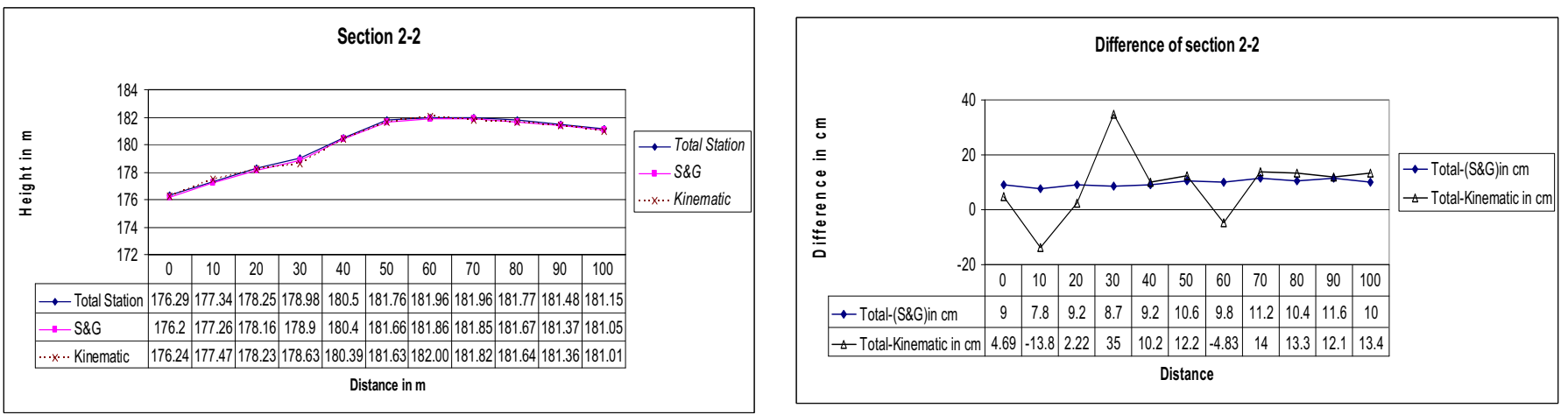

Fig. 7. Section (2-2) heights and height-difference from classical meas., (Stop\&Go) and Kin. GPS
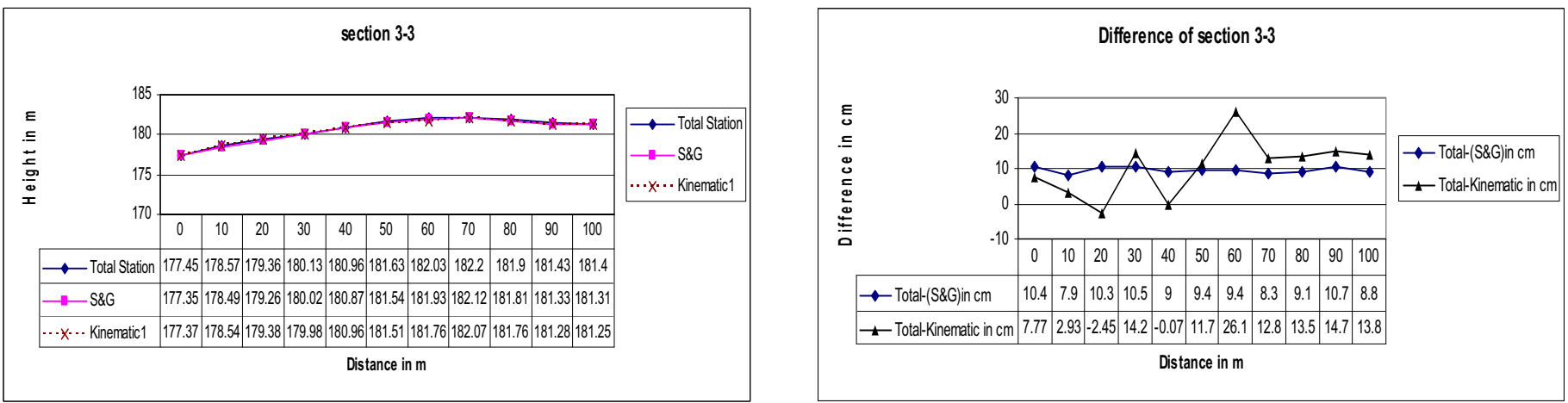

Fig. 8. Section (3-3) heights and height-difference from classical meas., (Stop\&Go) and Kin. GPS
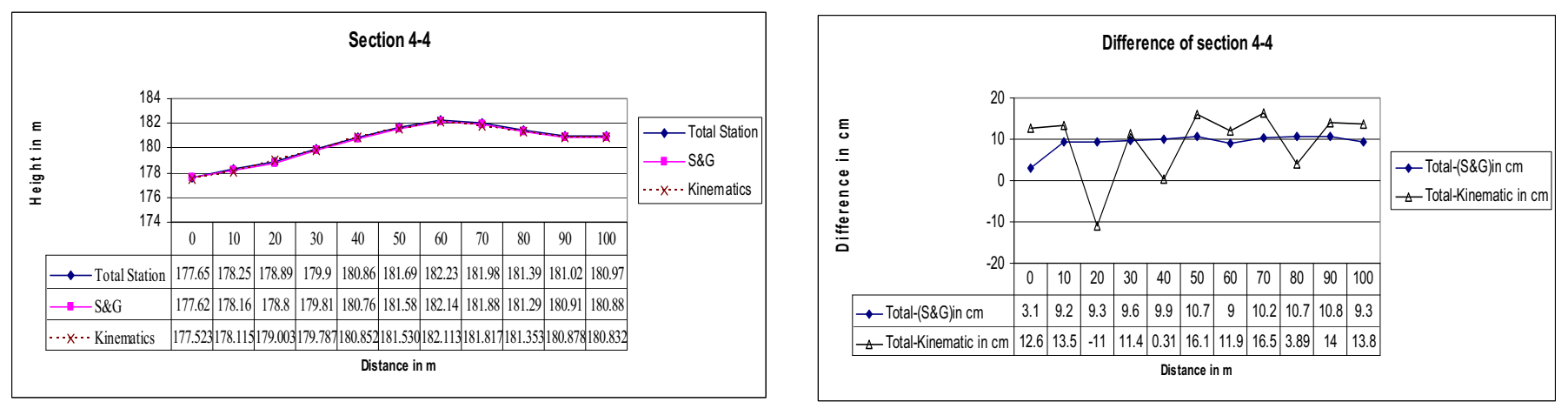

Fig. 9. Section (4-4) heights and height-difference from classical meas., (Stop\&Go) and Kin. GPS 

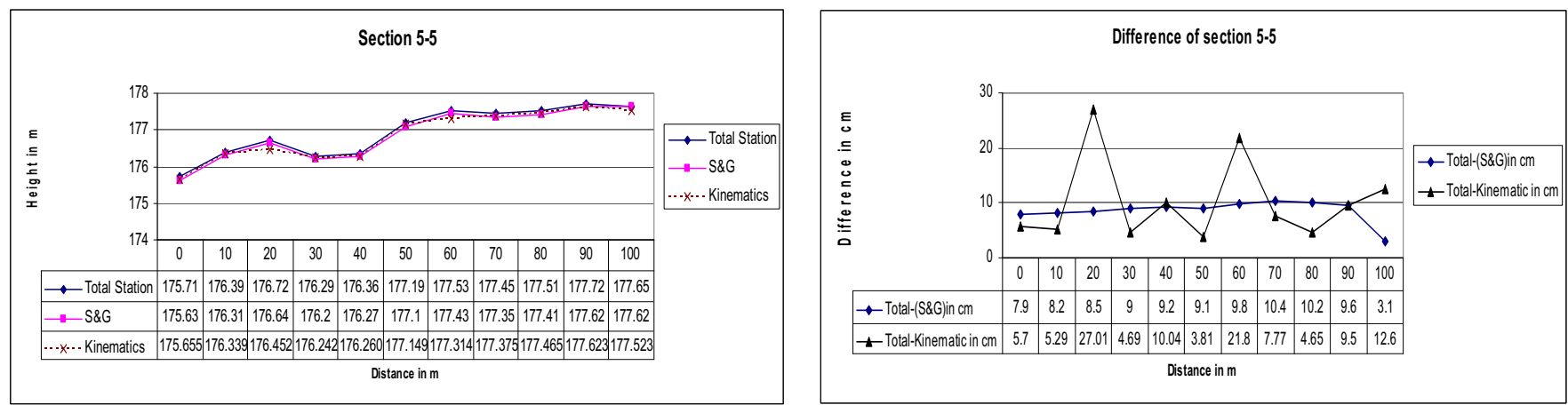

Fig. 10. Section (5-5) heights and height-difference from classical meas.(Stop\&Go) and Kin. GPS
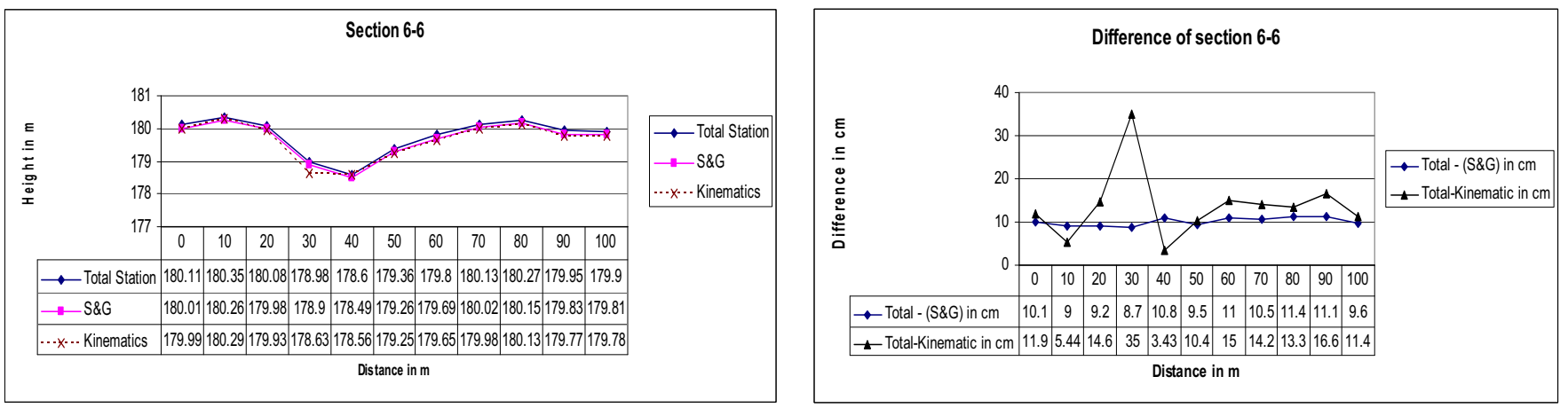

Fig. 11. Section (6-6) heights and height-difference from classical meas.(Stop\&Go) and Kin. GPS
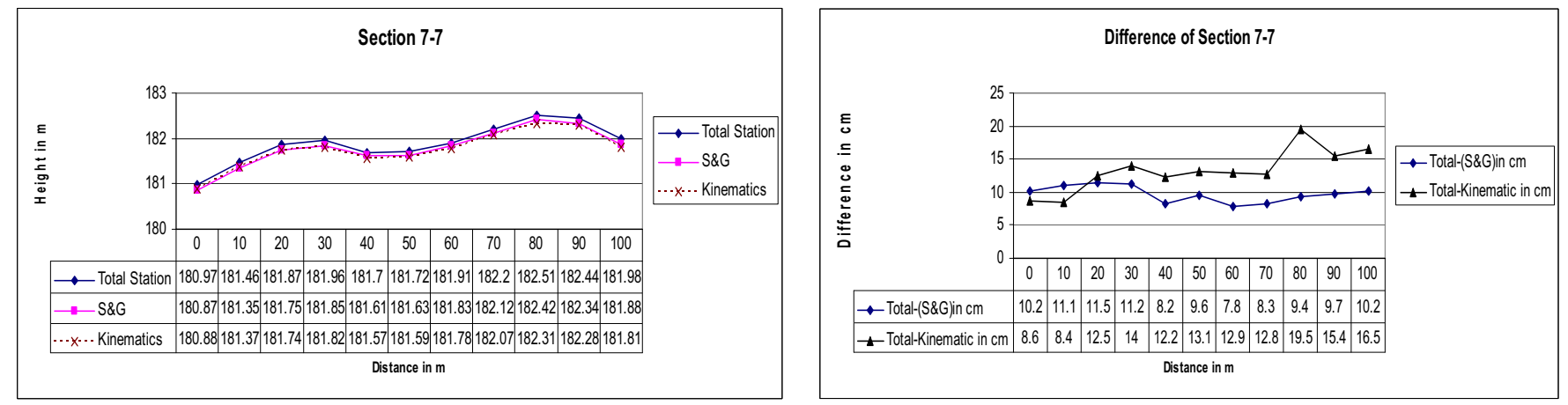

Fig. 12. Section (7-7) heights and height-difference from classical meas.(Stop\&Go) and Kin. GPS
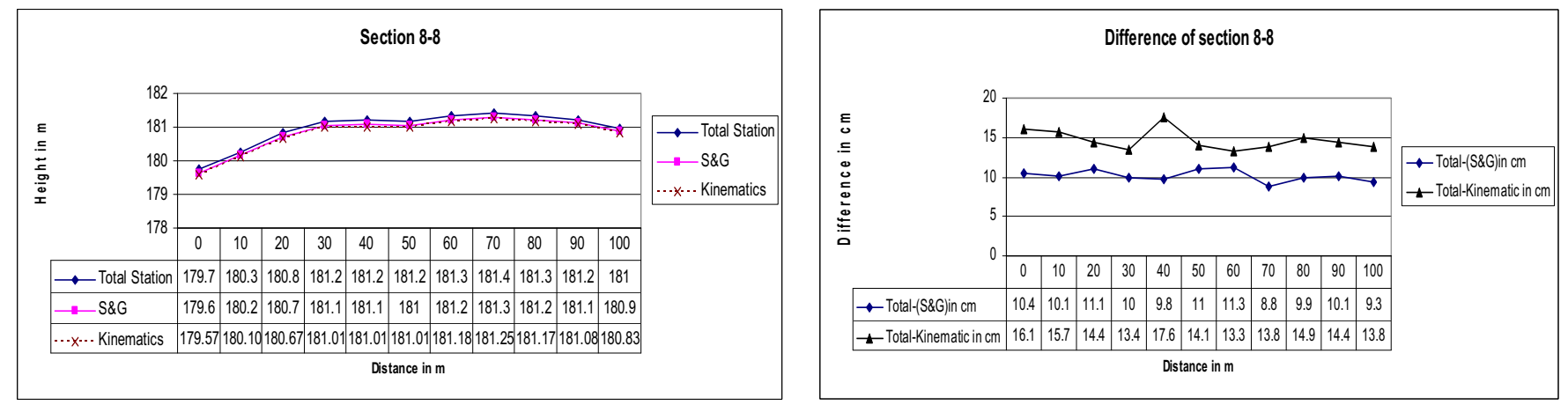

Fig. 13. Section (8-8) heights and height-difference from classical meas., (Stop\&Go) and Kin. GPS 
Table 1. Summary of the total area errors of the elevation profiles extracted from the (Stop\& Go) and Kinematic GPS against classical measurements (total station)

\begin{tabular}{|c|c|c|c|c|}
\hline $\begin{array}{c}\text { Observation } \\
\text { Technique }\end{array}$ & $\begin{array}{c}\text { Max. height } \\
\text { difference } \\
(\mathrm{cm})\end{array}$ & $\begin{array}{c}\text { Min. } \\
\text { height } \\
\text { difference } \\
(\mathrm{cm})\end{array}$ & $\begin{array}{c}\text { Standard } \\
\text { Deviation } \\
\text { height } \\
\text { difference } \\
(\mathrm{cm})\end{array}$ & $\begin{array}{c}\text { RMS height } \\
\text { difference } \\
(\mathrm{cm})\end{array}$ \\
\hline Stop\&Go & 11.6 & 3.10 & 1.06 & 9.70 \\
\hline Kinematic & 35.00 & -2.45 & 7.34 & 12.00 \\
\hline
\end{tabular}

Table 2. Summary of the errors of the elevation profiles extracted from the (Stop\& Go) and Kinematic GPS against classical measurements (total station)

\begin{tabular}{|c|c|c|c|c|c|}
\hline Section & Technique & $\begin{array}{c}\text { Max. height } \\
\text { difference } \\
(\mathrm{cm})\end{array}$ & $\begin{array}{c}\text { Min. } \\
\text { height } \\
\text { difference } \\
(\mathrm{cm})\end{array}$ & $\begin{array}{c}\text { Standard } \\
\text { Deviation } \\
\text { height } \\
\text { difference } \\
(\mathrm{cm})\end{array}$ & $\begin{array}{c}\text { RMS height } \\
\text { difference } \\
(\mathrm{cm})\end{array}$ \\
\hline \multirow{2}{*}{$1-1$} & Stop\&Go & 11.40 & 7.90 & 0.97 & 9.83 \\
\cline { 2 - 6 } & Kinematic & 33.70 & 5.70 & 7.39 & 15.83 \\
\hline \multirow{2}{*}{$2-2$} & Stop\&Go & 11.60 & 7.80 & 1.13 & 9.83 \\
\cline { 2 - 6 } & Kinematic & 35.00 & -13.80 & 12.39 & 14.82 \\
\hline \multirow{2}{*}{$3-3$} & Stop\&Go & 10.70 & 7.90 & 0.94 & 9.48 \\
\cline { 2 - 6 } & Kinematic & 26.10 & -2.45 & 8.03 & 12.93 \\
\hline \multirow{2}{*}{$4-4$} & Stop\&Go & 10.80 & 3.10 & 2.14 & 9.48 \\
\cline { 2 - 6 } & Kinematic & 16.50 & -11.00 & 8.38 & 12.31 \\
\hline \multirow{2}{*}{$5-5$} & Stop\&Go & 10.40 & 3.10 & 1.99 & 8.84 \\
\cline { 2 - 6 } & Kinematic & 27.01 & 3.81 & 7.59 & 12.55 \\
\hline \multirow{2}{*}{$6-6$} & Stop\&Go & 11.40 & 8.70 & 0.93 & 10.12 \\
\cline { 2 - 6 } & Kinematic & 35.00 & 3.43 & 8.11 & 15.78 \\
\hline \multirow{2}{*}{$7-7$} & Stop\&Go & 11.50 & 7.80 & 1.26 & 9.82 \\
\cline { 2 - 6 } & Kinematic & 19.50 & 8.40 & 3.19 & 13.61 \\
\hline \multirow{2}{*}{$8-8$} & Stop\&Go & 11.30 & 8.80 & 0.76 & 10.17 \\
\cline { 2 - 6 } & Kinematic & 17.60 & 13.30 & 1.31 & 14.74 \\
\hline
\end{tabular}

\section{DISCUSSIONS\&CONCLUSIONS}

In this study the (post-processed) GPS (Stop\& Go) and Kinematic techniques were used to generate DEM for rural area and then compared with the DEM generated using classical surveying measurements (total station). It can concluded that the (Stop\& Go) technique is following very close the behaviour of classical measurements with height-differences from (3.1 
$\mathrm{cm}$ to $11.6 \mathrm{~cm})$ with average standard deviation value of $(1.06 \mathrm{~cm})$ and RMS value of $(9.7 \mathrm{~cm})$. The Kinematic GPS technique is presenting a good accuracy as well in following the classical measurements behaviour with height-differences from $(-2.45 \mathrm{~cm}$ to $35 \mathrm{~cm})$ with average standard deviation value of $(7.34 \mathrm{~cm})$ and RMS value of $(12.00 \mathrm{~cm})$.

Four sections were analyzed in (east-west) direction. They present height difference standard deviation value of $(0.94 \mathrm{~cm}$ to $2.14 \mathrm{~cm})$ and RMS value of $(9.48 \mathrm{~cm}$ to $9.83 \mathrm{~cm})$ for Stop\& Go technique. Kinematic technique offers height difference standard deviation value of $(7.39 \mathrm{~cm}$ to $12.39 \mathrm{~cm})$ and RMS value of $(12.31 \mathrm{~cm}$ to $15.83 \mathrm{~cm})$.

Four sections were analyzed in (north-south) direction. They present height difference standard deviation value of $(0.76 \mathrm{~cm}$ to $1.99 \mathrm{~cm})$ and RMS value of $(8.84 \mathrm{~cm}$ to $10.17 \mathrm{~cm})$ for Stop\& Go technique. Kinematic technique offers height difference standard deviation value of $(1.31 \mathrm{~cm}$ to $8.11 \mathrm{~cm})$ and RMS value of $(12.55 \mathrm{~cm}$ to $15.78 \mathrm{~cm})$.

It can be concluded that Stop\& Go technique gives better accuracy than Kinematic technique with better values for standard deviation and root mean square while using kinematic technique is better in saving time and cost. Using GPS techniques for DEM generation gives good accuracy for civil engineering applications and region planning with significant safe in cost, time and labour.

\section{REFERENCES}

Blomgren, S. (1999). "A digital elevation model for estimating flooding scenarios at the Falsterbo Peninsula", Environmental Modelling \& Software, 14(6), 579-587.

Greve, C. \& American Society for Photogrammetry \& Remote Sensing. (1996). Digital Photogrammetry : An Addendum to the Manual of Photogrammetry, Bethesda, Md., American Society for Photogrammetry \& Remote Sensing.

Habib, A., (2005), Digital Terrain Modeling, Lecture Notes, www.geomatics.ucalgary.ca

Ibrahim Y1lmaz, Ibrahim Tiryakioglu, Fatih Taktak, Murat Uysal (2006)." Using RTK GPS Method in Creation of Digital Terrain Models ". International conference on cartography and GIS. Borovets,Bulgaria. January 25-28, 2006.

Mikhail, E.M., J.C. McGlone \& J.S. Bethel (2001). Introduction to Modern Photogrammetry, New York, Chichester, Wiley.

ProMark 3 manual (2005). Thales Navigation company.

Riley, S., N. Talbot \& G. Kirk (2000). "A new system for RTK performance evaluation", IEEE Position Location \& Navigation Symposium.

Sugumaran, R., C.H. Davis, J. Meyer \& T. Prato (2000). "High resolution digital elevation model and a web-based client-server application for improved flood plain management", IEEE Geoscience \& Remote Sensing Symposium IGARSS 2000.

Received: 2009-04-01,

Reviewed: 2009-07-01, by A. Ciećko,

Accepted: 2009-08-07. 